\title{
LETRAMENTO: ENTRE CONTOS E HISTÓRIAS EM QUADRINHOS
}

\author{
G. K. M. CARVALHO ${ }^{1}$, C. K. F. M DANTAS ${ }^{2}$, M. A. C. AGUIRRE ${ }^{3}$ \\ Universidade Federal do Rio Grande do Norte ${ }^{1,3}$ \\ Instituto Federal de Educação, Ciência e Tecnologia do Rio Grande do Norte ${ }^{2}$ \\ giselymedeiros@gmail.com ${ }^{1}$ \\ Artigo submetido em 26/01/2019 e aceito em 25/11/2019 \\ DOI: $10.15628 /$ holos. 2019.8240
}

\section{RESUMO}

Apresenta o desenvolvimento e o impacto do projeto de extensão "Ações de Letramento Familiar: a transmissão da cultura são-gonçalense" desenvolvido pela Universidade Federal do Rio Grande do Norte. O projeto extensionista levou para uma escola de zona rural atividades que visavam despertar nos alunos o reconhecimento de eventos e práticas de letramento, para que a partir disso eles pudessem perceber quais as suas principais demandas relacionadas à leitura e à escrita e, ao mesmo tempo, refletir acerca de aspectos socioculturais de seu contexto. Um trabalho desenvolvido com a realização de oficinas que permitiram aos alunos explorar socialmente a escrita através de produções textuais próprias. Nessa perspectiva, as ações da equipe proporcionaram o uso de diversos gêneros textuais, entretanto, destacam-se aqui os contos e as histórias em quadrinhos.

PALAVRAS-CHAVE: Projeto de Extensão, Letramento, Contos, Histórias em Quadrinhos.

\section{LITERACY: BETWEEN TALES AND COMICS}

\begin{abstract}
It presents the development and impact of the extension project "Ações de Letramento Familiar: a transmissão da cultura são-gonçalense" developed by the Universidade Federal do Rio Grande do Norte. The extension project implemented activities in a rural school with the intention of drawing students' attention to the recognition of literacy events and practices. This would allow the learners to understand their main demands related to reading and writing and, at the same time, to reflect on
\end{abstract}

the sociocultural aspects of their context. The results evidenced that the students socially explored the writing through the textual productions developed by them during the application of the project workshops. In this perspective, the actions of the project team provided students with the use with the use of many textual genres. The tales and comics have gained special prominence.

KEYWORDS: Extension Project, Literacy, Tales, Comics. 


\section{APRESENTAÇÃO}

Os atuais estudos de letramento expõem a ideia de que leitura e escrita são práticas discursivas permeadas de múltiplas funções e indissociáveis dos contextos onde se desenvolvem (KLEIMAN, 2007). Diante desta premissa, no ano de 2016, o grupo de pesquisa "O habitus de estudar: construtor de uma nova realidade na educação básica da região metropolitana de Natal" da Universidade Federal do Rio Grande do Norte (UFRN), com apoio do programa Observatório de Educação e da Coordenação de Aperfeiçoamento de Pessoal do Nível Superior (CAPES), implementou o projeto de extensão "Ações de Letramento Familiar: a transmissão da cultura sãogonçalense".

O projeto foi executado com uma turma do 50 ano do Ensino Fundamental, cabendo destacar que a seleção desses participantes não aconteceu de maneira aleatória, pois o professor titular da turma identificou em seus alunos históricos similares no que diz respeito a consideráveis dificuldades na aprendizagem de leitura e escrita.

Assim, numa atuação conjunta, buscou-se compreender o que seria significativo para atender aquela classe escolar - os pesquisadores do projeto empreenderam inúmeros diálogos junto à equipe pedagógica e aos pais.

A partir de encontros semanais, o projeto buscou provocar reflexões e desenvolver nos alunos habilidades para o exercício competente, crítico e criativo dos atos de ler e escrever, além de ampliar suas práticas sociais de leitura e escrita. Focava-se, com base em Kleiman (2007), no impacto social que a escrita provoca, com a percepção de que as mudanças e as transformações sociais decorrentes das novas tecnologias e dos novos usos da escrita têm profundo significado. Contemplando a concepção fundamental do letramento: ler e escrever para agir no mundo social.

Diante do exposto, apresenta-se aqui o desenvolvimento e o impacto do projeto de extensão "Ações de Letramento Familiar: a transmissão da cultura são-gonçalense". Mas, antes disso, expõe-se o embasamento teórico que norteou a atuação do projeto.

\subsection{Letramento e gêneros textuais: diálogo de saberes}

Quando o ensino se baseia no conceito de letramento, passa a promover o uso e/ou apoio a diversos gêneros textuais, especialmente os que circulam no dia a dia do educando. Isso requer do professor, além do domínio de conteúdo, um olhar especial para os conhecimentos prévios do alunado, a consideração da bagagem cultural e dos fatos de seu entorno.

Coe (2002, p. 197) aponta que gênero textual não "é um tipo de texto nem um tipo de situação", mas um constituinte de uma relação funcional entre texto e contexto. Tal colocação explica o porquê de o gênero textual estar intimamente relacionado com os atos informacionais habituais da vida em sociedade.

Nessa mesma concepção, Marcuschi (2009) esclarece que: 
gêneros textuais são textos que encontramos em nossa vida diária e que apresentam padrões sociocomunicativos característicos definidos por composições funcionais, objetivos enunciativos e estilos concretamente realizados na integração de forças históricas, sociais, institucionais e técnicas (p. 155).

Diante do pensar e do refletir o trabalho com gêneros textuais em sala de aula, toma-se o entendimento de projetos de letramento definido por Kleiman (2000, p. 238), que afirma que "as práticas de letramento decorrem de um interesse real na vida dos alunos, servindo para atingir algum outro fim que vai além da mera aprendizagem da língua, no seu aspecto formal".

Segundo Oliveira (2010), os projetos de letramento fazem parte de uma cultura escolar alternativa, pois a construção do conhecimento orienta-se a partir da "resolução de problemas". Tem procedência na prática social e, com ações coletivas, supre necessidades sociais e demandas comunicativas específicas do grupo onde atua. Cabe observar que, no Brasil, os projetos de letramento não são muito recorrentes nas salas de aula, especialmente porque requerem um trabalho mais dedicado, no qual o professor precisa empreender esforços, sobretudo para reconhecer características pertinentes ao contexto dos alunos.

Frente aos desafios da sociedade atual, intensamente permeada pelos mais abundantes tipos de informação, entende-se que é imprescindível o professor abarcar o letramento como uma alternativa pedagógica relevante, principalmente quando se trata de alunos da Educação Básica, os quais precisam de incentivos reais para que possam desenvolver diferentes práticas de leitura e escrita. Ou seja, os letramentos devem ser nutridos.

Contempla-se a ideia de que projetos de letramento trazem um enfoque socialmente contextualizado para a sala de aula. Quanto a isso, Kleiman (2007) afirma que o trabalho do professor deve ter como ponto de partida a bagagem cultural e diversificada dos alunos, os quais precisam ter contato com textos que circulam na vida social, pois deste modo poderão vencer os entraves que a leitura de tais textos pode apresentar.

Sabendo que as situações de interação social propiciam às pessoas o uso da língua de forma específica em contextos específicos, compreende-se que, a partir de situações sociais de uso da língua, é possível fundamentar projetos de letramento empenhados no desenvolvimento de trabalhos socialmente significativos que acionam os mais diversos gêneros textuais.

Admite-se, portanto, que o texto abrange funções socioculturais que precisam ser observadas no espaço escolar. Não é à toa que os Parâmetros Curriculares Nacionais assumem que "a prática de produção de textos precisa realizar-se num espaço em que sejam consideradas as funções e o funcionamento da escrita, bem como as condições nas quais é produzida: para que, para quem, onde e como se escreve" (BRASIL, 1997, p. 49).

Posto isso, o projeto "Ações de Letramento Familiar: a transmissão da cultura sãogonçalense" buscou estimular práticas sociais letradas, bem como incentivar alunos e professores a se tornarem agentes de interação social mobilizadores de letramento. Ou seja, agentes de letramento.

Os agentes de letramento atuam com gêneros textuais, que são como pontes para o aprendizado dos padrões comunicativos do cenário social. Eles buscam desenvolver competências 
múltiplas, no que diz respeito à interação com o texto, e se apropriam de conhecimentos específicos, a saber, quando, em que e como aplicar cada gênero textual. Passam a ter consigo uma ferramenta de poder (a compreensão da linguagem social) que os torna agentes mobilizadores.

Reforça-se que o projeto aqui apresentado estava ancorado no uso social da linguagem, já que explorou e manteve o contato dos alunos com muitos textos que circulam na sociedade, conforme a demanda do grupo. Porém, a ênfase deste estudo recai no trabalho com "contos populares" e "histórias em quadrinhos", gêneros textuais de tipologia narrativa, que permeiam o público participante do projeto e garantem a percepção de aspectos como enredo, imagens, ludicidade, etc. devido a "aproximação na composição formal dos dois gêneros" (AMARILHA, 2009, p. 1).

O conto é uma narrativa, de certa forma, condensada. Apresenta poucas personagens e tem tempos e espaços específicos. Em geral, o conteúdo desse gênero não se alonga por muitas páginas, suas informações são precisas. De acordo com Bosi (1975, p. 31), é uma espécie de "poliedro capaz de refletir as situações mais diversas de nossa vida real ou imaginária". Mas, a definição de conto popular é um pouco mais complexa devido a sua multiplicidade.

De formato simples e linguagem aberta, o conto popular demarca o encontro entre memória e imaginação, traz junto a si um aparato histórico e sociocultural, pois é "um documento vivo, denunciando costumes, ideias, mentalidades, decisões e julgamentos." (CASCUDO, 2002, p. 10). A estrutura desse tipo de conto relata vivências simples e sofre modificações linguísticas conforme época e região. Além disso, apresenta vestígios de tradições e concepções arraigadas em contextos histórico-culturais peculiares.

Deste modo, há que se considerar que no ambiente escolar, o trabalho com contos populares a partir de projetos de letramento pode permitir aos envolvidos o desenvolvimento da criticidade e da consciência de ampliação de seu repertório social, cultural e linguístico. Possibilita, assim, formar leitores que percebem a vida a partir de olhares diferenciados.

Em se tratando do gênero textual histórias em quadrinhos, Braga Junior (2012, p. 16) define como "produções midiáticas vinculadas ao mundo do entretenimento e da expressão artística, [...] publicações impressas ou digitalizadas, que narram, através de uma sequência de imagens desenhadas, situações das mais diversas". Nunes e Trescastro (2016) afirmam ser um gênero multimodal devido acionar um conjunto de signos verbais e visuais que se combinam numa sucessão de episódios e compõem uma narrativa. Portanto, esse é o traço mais característico das histórias em quadrinhos: a linguagem mista (verbal e não verbal), que atrai diferentes públicos.

É necessário destacar que os recursos textuais e discursivos das histórias em quadrinhos promovem estratégias que são eficazes para desenvolver o letramento. $O$ formato multimodal desse gênero conduz o leitor a uma leitura mais atenciosa e, ao mesmo tempo, o faz despertar para questões periféricas e subentendidas. Isto é, aquelas que não necessariamente estão expressas de maneira escrita (SANTOS; VERGUEIRO, 2012).

Atualmente, muitas são as exigências para que leitores compreendam e dominem os mais distintos gêneros. Nessa perspectiva, Tavares (2015) afirma que é imprescindível estimular práticas 
de letramento fazendo com que o aluno possa reconhecer e explorar diversos textos, passe a notar as diferenças e/ou semelhanças existentes entre eles, bem como perceber que a linguagem se diferencia conforme o gênero. Isto é, ao conseguir distinguir a linguagem utilizada em cada texto, o educando passa a saber acionar mais facilmente os recursos textuais e discursivos em qualquer momento de sua vida social.

\section{SUJEITOS E ASPECTOS METODOLÓGICOS}

Participaram do projeto vinte e um alunos de uma turma do 5o ano do Ensino Fundamental, 2016, da Escola Municipal José Horácio de Gois. A instituição escolar pública está situada na comunidade de Guanduba, zona rural do município de São Gonçalo do Amarante, Rio Grande do Norte (RN). Os alunos tinham faixa etária entre 10 (dez) e 12 (doze) anos de idade.

Para a coleta de dados, utilizou-se a observação participante, que é uma técnica de investigação em que o pesquisador se insere no contexto e passa a captar as falas, os gestos, as experiências - ações subjetivas relacionadas à interação social dos sujeitos da pesquisa. Essa técnica, de acordo com Gil (2010), admite um olhar mais amplo em relação ao grupo pesquisado, e supõe interação entre o pesquisador e os sujeitos pesquisados.

O responsável pela observação se insere no contexto de modo partícipe "e, sem dúvida, modifica esse contexto, pois interfere nele, assim como é modificado pessoalmente" (MINAYO, 2013, p. 70).

No decurso do projeto, diversas ocorrências e fatos foram observados e registrados num diário de campo, o qual era alimentado sempre após a imersão dos pesquisadores no contexto investigado. Com base nesse diário de campo, foi possível desenvolver este trabalho que contempla uma breve descrição do projeto desenvolvido e ressalta as impressões e interpretações dos pesquisadores, discutidas na seção seguinte.

\section{VIVÊNCIAS DE UM PROJETO DE LETRAMENTO EM SALA DE AULA}

Considera-se aqui o aproveitamento alcançado pelo projeto de extensão "Ações de Letramento Familiar: a transmissão da cultura são-gonçalense", que empreendeu um trabalho focado no letramento e abalizado no reconhecimento e uso de gêneros textuais. Sendo, estes gêneros uma "ponte" que intermedia o conhecimento prévio dos alunos e o desenvolvimento de práticas sociais de leitura e escrita.

Quanto aos procedimentos implantados, a parte inicial teve suma importância porque produziu um levantamento diagnóstico das práticas sociais de leitura e escrita mais recorrentes entre os participantes, esclareceu como ocorreriam as oficinas de letramento do projeto e que tipo de ação seria desenvolvida. Foi um momento de apresentações, em que os alunos tiveram o primeiro contato com os agentes de letramento do projeto, receberam orientações e fizeram perguntas pertinentes. Após essas sondagens, iniciaram-se os encontros com formato de oficinas.

As explorações junto a turma esclareceram que aqueles estudantes estavam habituados com atividades copistas, tarefas que não instigam a imaginação e que, de acordo com Street 
(2014), são trabalhos e produções textuais que não problematizam sentidos e conteúdo, têm foco na forma. Sabendo disso, buscou-se a prática de leitura e escrita acionando sempre o contexto dos educandos.

\subsection{Oficinas de letramento: os novos olhares}

A oficina de abertura do projeto de extensão "Ações de Letramento Familiar: a transmissão da cultura são-gonçalense" partiu da indagação "O que é Cultura?". Numa roda de conversa, perguntou-se aos alunos quais entendimentos tinham acerca da "cultura". Dentre várias informações apresentadas em pequenos cartazes, eles procuraram a melhor definição para o termo. Essa oficina teve um tema gerador, pois buscava-se uma observação mais robusta acerca das perspectivas e potencialidades das práticas sociais de leitura e escrita dos alunos.

Em oficinas posteriores, foram exibidos filmes e animações que expunham símbolos e personalidades do estado do Rio Grande do Norte e da cidade São Gonçalo do Amarante. Os alunos apreciaram e reconheceram quase todos. Todavia, percebeu-se a necessidade de apresentar/falar sobre pessoas que representam a cultura local (de Guanduba). Assim, os alunos citaram alguns nomes e, dentre eles, o nome da senhora Rita Pereira prevaleceu como personalidade representativa da comunidade (notoriamente reconhecida pelos trabalhos de teatro, música e dança). Porém, nem todos a conheciam. Com isso, realizou-se um trabalho com o gênero textual "biografia" que resultou numa investigação e busca de informações junto a familiares e amigos, alcançando a própria Sra. Rita. A turma expôs um material sobre a vida e a obra dessa pessoa tão ilustre.

Também esteve presente nas oficinas, a literatura de cordel. Os alunos leram textos de cordéis, falaram e refletiram sobre a composição e a estrutura desse gênero textual e, inspirados nas Olimpíadas e Paraolimpíadas do Rio de Janeiro 2016, puderam expor seus pensamentos. Assim, ao longo de dois encontros com os agentes de letramento, os alunos produziram desenhos em formato de xilogravuras e cuidadosamente pensaram nas rimas. Cabe reforçar, que o apoio da professora titular da turma foi essencial, uma vez que essa agente formadora conhecia profundamente a elaboração de versos de cordel. Cada aluno apresentou pessoalmente a sua produção e o resultado ficou exposto num cordão fixado numa parede do pátio da escola.

Algumas oficinas abordaram a temática da "alimentação saudável" (Figura 1). Uma delas teve como atividade a apresentação de uma mesa repleta de alimentos que, em geral, são servidos no café da manhã dos lares nordestinos e, diante deste cenário, os alunos deveriam compor uma refeição matinal escolhendo alimentos com alto teor de valor energético. O passo seguinte era fazer um "relato pessoal" (gênero textual que tem a característica de retratar experiências cotidianas) sobre a alimentação diária. Deste modo, cada aluno teve a oportunidade de fazer seu relato pessoal, que foi gravado em vídeo e apresentado em sala de aula. 


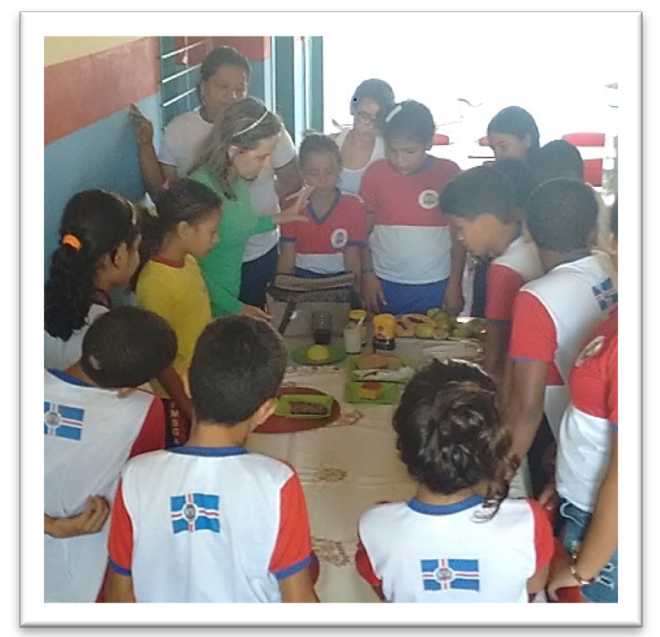

Figura 1: Diálogo com os alunos sobre alimentação saudável.

Durante a atuação destas oficinas, foi possível trocar ideias e conhecer as impressões dos alunos com relação ao uso de gêneros textuais. Pode-se afirmar que esses encontros serviram de "pontapé inicial" para explorar saberes que estavam adormecidos.

\subsection{Oficinas de letramento: ações com histórias em quadrinhos}

Conforme dito anteriormente, o projeto fez uso do gênero textual histórias em quadrinhos (HQ) nas suas oficinas. Tomou base Santos e Vergueiro (2012, p. 93), que consideram que atuar com histórias em quadrinhos na escola, a partir de atividades práticas, confere mais dinamicidade ao ensino e prazer na aprendizagem.

Ressalta-se que o trabalho com histórias em quadrinhos compreendeu três etapas:

(1) Exploração de HQ: envolveu diálogos para averiguar quais os conhecimentos prévios dos participantes e a apresentação de fatos e curiosidades atinentes às histórias em quadrinhos. Esta etapa abarcou conversas e debates, bem como a apreciação do gênero textual em questão, o que permitiu desenvolver habilidades de leitura crítica e reflexiva.

(2) Imersão no mundo HQ: abrangeu o contato direto por meio de leituras, interpretações e discussões acerca de histórias em quadrinhos. Esse momento foi reservado para que os alunos utilizassem um esquema norteador, guia de leitura que permitia a identificação de elementos característicos do gênero, tais como o uso de linguagens verbal e não verbal, balões, sequências de tirinhas, relação entre as falas e os tipos de balões e a recorrência de onomatopeias (Figura 2).

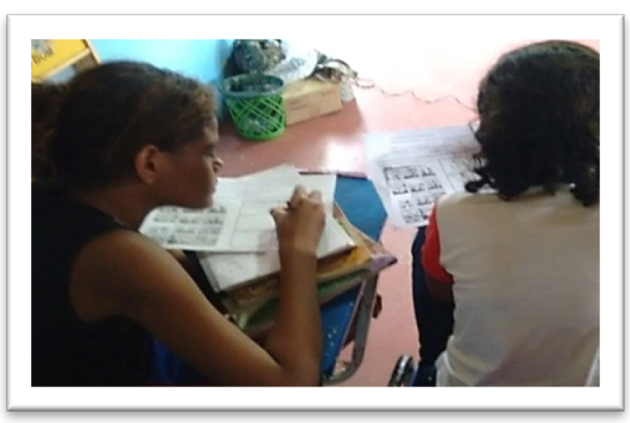

Figura 2: Alunas utilizando o esquema norteador. 
(3) Elaboração de HQ: a partir da apresentação de vídeos que descreviam o passo a passo para elaborar uma história em quadrinhos e com apoio dos agentes de letramento do projeto, chegou-se à fase da criação que também envolveu roteiros previamente organizados para auxiliar na montagem dos desenhos e textos. Os educandos, então, puseram em prática os conhecimentos adquiridos e construíram suas próprias histórias em quadrinhos (Figura 3). Nesse ínterim, foi possível deleitar-se com as produções verbo-visuais que vislumbravam fatos do cotidiano dos alunos. É claro que, como em todo texto escrito, houve o trabalho da reescrita - a realização de ajustes estruturais para dar sentido lógico ao texto e a adequação às normas ortográficas e/ou gramaticais.

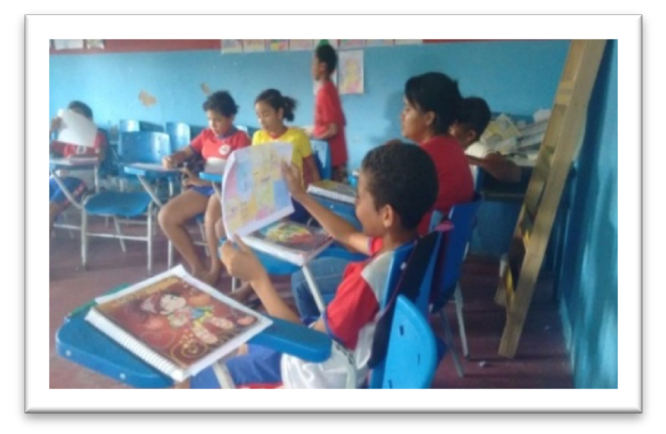

Figura 3: Aluno apresentando a sua própria história em quadrinhos.

A cada etapa vivenciada, percebia-se que os educandos conseguiam dar conta dos conhecimentos que o gênero histórias em quadrinhos proporciona. Esse trabalho revelou que os estudantes podem alcançar percepções que vão além do texto, pois demonstraram plena capacidade para reconhecer elementos como os ângulos, os planos de visão e os traços expressivos de personagens, os quais autorizam outras formas de leitura.

\subsection{Oficinas de letramento: contando contos}

Dentre as oficinas com mais discussão e trabalho, estavam as oficinas de contos. Nelas o aluno era levado a ler, a compreender e a produzir textos com sentidos. O início do trabalho com esse gênero aconteceu quando os alunos receberam cadernos como presente do Dia das Crianças. Sugeriu-se que escrevessem ali histórias interessantes, relacionadas com a vida diária e que abordassem questões e conhecimentos significativos para eles. Produções textuais que eram lidas no decorrer das ações do projeto e reescritas para aprimoramento da leitura e escrita.

Num momento posterior, apresentou-se a animação "Calango Lengo - Morte e Vida Sem Ver Água" (2008), uma releitura do poema Morte e vida Severina de João Cabral de Melo Neto. Numa observação mais aprofundada, percebeu-se que essa animação também expunha recortes de muitos contos populares brasileiros. Ou seja, os alunos tiveram contato com um gênero textual que abrangia inúmeros outros gêneros e o intertexto. Decerto, essa oficina teve relevância porque os estudantes apontaram as impressões geradas a partir daquela visualização e perceberam que o enredo se assemelhava a acontecimentos de suas reais histórias de vida.

Uma outra oficina contemplou a apresentação encenada do texto "O conto se apresenta", de Moacyr Scliar (2002), que envolveu os alunos numa trama. Eles receberam de presente uma 
caixa abarrotada de papéis e, em cada um destes, havia um conto. Os estudantes escolheram aleatoriamente o seu conto (Figura 4) e, em seguida, foram convidados a ler para a turma.

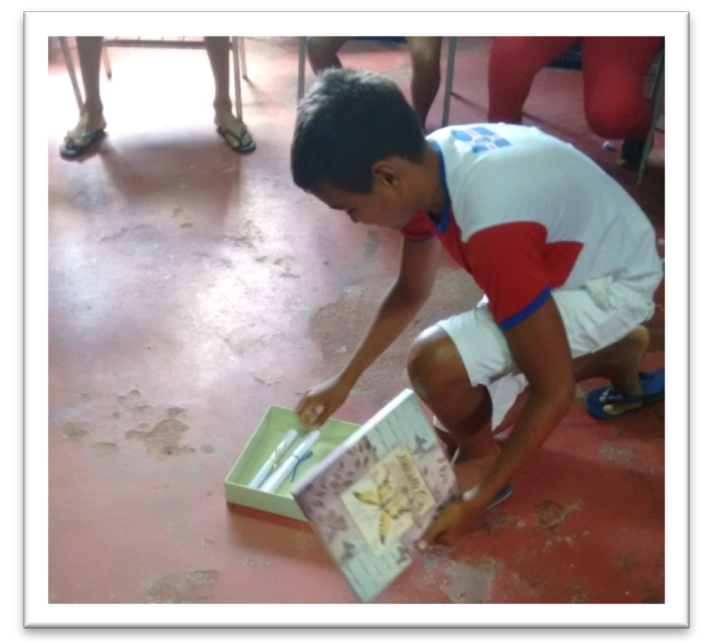

Figura 4: Aluno retirando um conto da caixa.

A atenção acerca dos detalhes do conto (partes e como se constrói) também aconteceu nas oficinas, já que muitos contos foram lidos e, posteriormente, desmembrados para a identificação de personagens, espaço, tempo, apresentação, problema, clímax e desfecho das narrativas. Para tanto, criaram-se painéis que expunham os contos e como eles se estruturavam, os quais foram fixados nas paredes da sala de aula (Figura 5). Dessa forma, os educandos puderam compreender melhor a estruturação de um conto.

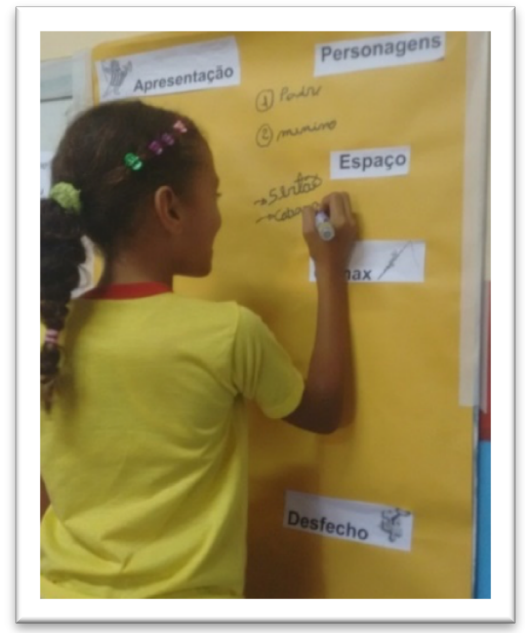

Figura 5: Aluna preenchendo painel com detalhes de conto lido em sala de aula.

A partir do contato com diversos tipos de contos, os quais foram disponibilizados e lidos em sala de aula, sugeriu-se o trabalho com produção textual coletiva: elaborar um conto com apoio de toda a turma. Os alunos optaram por construir um conto misterioso, que se assemelhava com uma lenda, idealizaram as personagens, definiram os espaços e o enredo. Mas, havia um impasse: sequenciar o texto de maneira lógica. Problema que foi contornado com o auxílio dos agentes de letramento do projeto, que mobilizaram conhecimentos para que a turma pudesse estabelecer uma narrativa com sentido. Este trabalho foi finalizado com louvor, pois os participantes puderam apresentar a produção textual para demais integrantes da comunidade escolar. 
O trabalho com contos foi aprimorado porque os alunos achavam significante falar de suas vidas reais. Propôs-se, então, a produção de contos populares que, de acordo com Azevedo (1999), é um gênero textual que se relaciona com a literatura infantil por se apresentar a partir de textos concisos, marcados pela oralidade e por vocabulário que se mantém próximo ao leitor.

Nesse ínterim, achou-se interessante transformar as histórias em quadrinhos produzidas anteriormente em contos. Pois, conforme Amarilha (2009, p. 1) "o uso de palavras e imagens, representa [...] mais um fator que facilita o trânsito de um gênero para outro", especialmente ao considerar a incipiente experiência em leitura dos educandos. Ressalta-se que nem todos os participantes optaram pela transformação dos quadrinhos em contos. Alguns decidiram explorar novos enredos, produzir narrativas inéditas. Ficou a critério de cada aluno. A intenção era desenvolver a escrita dos alunos e aprimorar o entendimento acerca da estrutura e da aplicação do conto popular

Para Azevedo (2001) existem certos aspectos que vinculam a literatura infantil ao conto popular, dentre eles estão a comicidade, o uso da fantasia e da metamorfose, a busca da identidade e o final feliz. Quanto a isto, pode-se dizer que as oficinas do projeto ajudaram os alunos no sentido de instituir relações entre as vivências socioculturais de seu cotidiano e o texto literário. Principalmente porque os contos produzidos por eles retratavam ambientes (festas, fazenda, etc.) e pessoas de seu entorno, a exemplo, o vaqueiro.

Todos os contos produzidos pelos alunos foram minuciosamente trabalhados - passaram por revisões e receberam ajustes estruturais, de sentido e/ou de ortografia. Mas, identificou-se que alguns participantes fizeram cópias de textos de outros autores. Diante disso, a questão do plágio também foi discutida com o grupo. E, para aqueles que cometeram esse erro, deu-se a oportunidade de uma produção nova e autoral.

As produções textuais foram apreciadas por toda a turma numa exposição dialogada. Os alunos participantes fizeram apontamentos pertinentes ao trabalho realizado pelo projeto, afirmaram ter gostado das oficinas porque trouxeram atividades que possibilitavam momentos para pensar e discutir sobre a vida na comunidade, além de ajudarem na criação de textos originais que retratavam fatos da cultura local.

\subsection{Encerramento das oficinas}

Houve um evento de apresentação do material produzido pelos alunos. Uma exposição dos conhecimentos adquiridos, das habilidades e competências desenvolvidas. Os alunos tiveram a oportunidade de ler seus contos e expor suas histórias em quadrinhos para toda a comunidade escolar. Foi também um momento socializador, de diálogo aberto estabelecido entre os educandos, a equipe do projeto e os membros da Escola Municipal José Horácio de Gois.

Ao final, os alunos participantes foram presenteados com um kit de materiais escolares para que pudessem se sentir estimulados a dar continuidade as suas produções textuais e prosseguirem nos estudos. E, num ambiente especialmente reservado, todos puderam se confraternizar e saborear um lanche saudável.

Cabe esclarecer que a equipe do projeto encerrou suas atividades ao encaminhar um relatório à Universidade Federal do Rio Grande do Norte, o qual expunha a satisfação de ter 
ensejado àqueles alunos diversas experiências na construção de aprendizados significativos que promovem leitura e escrita com respostas sociais, isto é, ações de letramento que potencializam saberes.

\section{ALGUMAS CONSIDERAÇÕES}

Ações de letramento, especialmente quando alicerçadas pelo uso dos gêneros textuais, como contos e histórias em quadrinhos, proporcionam empoderamento aos alunos. Visto que, estes passam a expor, através da escrita, fatos recorrentes de seu meio social. Sobretudo, percebem e dão sentido as suas leituras e produções escritas.

Mas, é necessário esclarecer que as atividades do projeto de extensão "Ações de Letramento Familiar: a transmissão da cultura são-gonçalense" requisitaram o apoio e a participação de toda comunidade escolar. Ou seja, o comprometimento era geral. Notadamente porque os efeitos sentidos na aprendizagem dos participantes iriam se refletir na instituição como um todo.

As vivências com aqueles educandos proporcionaram aos pesquisadores o entendimento de que o projeto levou para aquela sala de aula de Guanduba mais estímulo às práticas sociais de leitura e escrita - em particular porque o trabalho dos agentes de letramento estava voltado para o contexto sociocultural do alunado. No que se refere a essa questão, uma das professoras observou que certos alunos da turma haviam melhorado os aspectos condizentes à leitura e à escrita após o envolvimento com as oficinas, as quais demonstravam a estreita relação das práticas de ler e escrever com o universo social e de interesses dos participantes.

A atuação dos agentes de letramento na turma do 5 o ano do Ensino Fundamental, 2016, da Escola Municipal José Horácio de Gois consentiu a efetivação de uma mobilização que ampliou o conhecimento das práticas sociais de leitura e escrita. E, agora, puxando os fios que cruzaram o tecer do projeto, é possível ter uma visão clara de o quanto os alunos evoluíram no tocante ao letramento. Pois, nas últimas oficinas ministradas, aqueles estudantes já demonstravam maior autonomia com relação à leitura e à escrita, além de apresentarem produções textuais que manifestavam questionamentos e respostas sociais.

Pode-se dizer que o trabalho do projeto trouxe para os estudantes daquela classe escolar uma contemplação de leitura e escrita alinhada às suas práticas socioculturais, pois todas as produções textuais desenvolvidas durante o projeto tinham real significância para as vidas dos educandos. $E$, no que concerne às contribuições desta experiência para os agentes de letramento, ressalta-se que este foi um trabalho que permitiu desenvolver maior sensibilidade para perceber e considerar as experiências de mundo que cada pessoa traz consigo.

\section{REFERÊNCIAS}

AMARILHA, M. (2009, set./dez.) História em quadrinhos e literatura infantil: a paródia na formação do leitor. Revista Educação em Questão, 36 (22), 56-73, Natal. 
AZEVEDO, R. (1999) Literatura infantil: origens, visões da infância e certos traços populares. Recuperado de http://www.ricardoazevedo.com.br/wp/wp-content/uploads/Literaturainfantil.pdf

AZEVEDO, R. (2001) Elos entre a cultura popular e a literatura. Recuperado de http://www.ricardoazevedo.com.br/wp/wp-content/uploads/Elos-entre-cultura-popular-eliteratura.pdf

BOSI, A. (1975) O conto brasileiro contemporâneo. São Paulo: Cultrix.

BRAGA JÚNIOR, A. X. (2012, abr.) Quadrinhos independentes: usando imagens para contar muito mais que história. Revista História, imagem e narrativas, n. 14. ISSN 1808-9895

BRASIL. (1997) Parâmetros curriculares nacionais: língua portuguesa. Brasília: Ministério da Educação/Secretaria de Educação Fundamental.

CALANGO LENGO. (2008) Morte e Vida Sem ver Água. Direção de Fernando Miller. Animação, 10 min. 35mm. São Paulo. Recuperado de https://www.youtube.com/watch?v=bh5GtyPOPK4

CASCUDO, L. C. (2002) Contos tradicionais do Brasil. (18a ed.). Rio de Janeiro: Ediouro.

COE, R. M. (2002) The new rhetoric of genre: writing political briefs. (pp. 197-210). In: JOHNS, A. M. (Ed.). Genre in the classroom: multiple perspectives.

GIL, A. C. (2010). Como elaborar projetos de pesquisa. (5a ed.). São Paulo: Atlas.

KLEIMAN, A. B. (2000) O processo de aculturação pela escrita: ensino de forma ou aprendizagem da função? (pp. 223-243). In: KLEIMAN, A. B., \& SIGNORINI, I. (Orgs.). O ensino e a formação do professor: alfabetização de jovens e adultos. Porto Alegre: Artes Médicas do Sul.

KLEIMAN, A. B. (2007) O conceito de letramento e suas implicações para a alfabetização. (Projeto Temático Letramento do Professor). UNICAMP.

MARCUSCHI, L. A. (2009) Gêneros Textuais \& Ensino. (5a ed.). São Paulo: Lucerna.

MINAYO, M. C. S. (Org.). (2013). Pesquisa social: teoria, método e criatividade. (33a ed.). Petrópolis, RJ: Vozes.

NUNES, L. P., \& TRESCASTRO, L. B. (2016, jul./dez.) Do filme à história em quadrinhos: um trabalho de retextualização no 4ำ ano do ensino fundamental. Entrepalavras, 6 (2), 353-369, Fortaleza.

OLIVEIRA, M. S. (2010) Gêneros textuais e letramento. Revista Brasileira de Linguística Aplicada, 10 (2), 325-345, Belo Horizonte.

SANTOS, R. E., \& VERGUEIRO, W. (2012, jan./abr.) Histórias em quadrinhos no processo de aprendizado: da teoria à prática. EccoS Revista Científica, (27), 81-95, São Paulo.

SCLIAR, M. (2002) O conto se apresenta. São Paulo: Editora Cia. das Letrinhas. 
STREET, B. (2014) Letramentos sociais: abordagens críticas do letramento no desenvolvimento, na etnografia e na educação. (M. Bagno, Trad.) São Paulo: Parábola Editoria.

TAVARES, L. H. M. C. (2010, jul./dez.) Gêneros e multimodalidade discursiva nas histórias em quadrinhos. Revista Prolíngua. 5(2). 